\title{
FELICIDADE: UMA PONDERAÇÃO SOBRE A PERSPECTIVA DA SOCIEDADE CONTEMPORÂNEA
}

\author{
Pamela Dolores Teixeira ${ }^{1}$ \\ José Fabiano Ferraz ${ }^{2}$ \\ Ana Cabanas ${ }^{3}$
}

Resumo: A fragilidade dos relacionamentos e o aumento pela busca do poder aquisitivo na sociedade contemporânea interfere na felicidade humana. Assim, nesta investigação, o propósito foi ponderar sobre o fenômeno da felicidade na perspectiva psicológica sócio-histórico que possibilita a avaliação do caráter social e as interferências do estilo de vida. Para isso, nesta pesquisa bibliográfica com caráter qualitativo se utilizou o método de abordagem dedutivo e dialético e método de procedimento fenomenológico e funcionalista. O fenômeno da felicidade na sociedade contemporânea se construiu a partir de um sistema econômico, e a compreensão pós-moderna modificou a estrutura e o estilo de vida das pessoas. Em uma perspectiva sócio-histórico a felicidade na sociedade contemporânea adquire formas mercantis e instiga os sujeitos a fazer parte do ciclo consumista.

Palavras-chave: Modernidade; Sociedade contemporânea; Aspectos sócio-histórico; Capitalismo; Felicidade.

\footnotetext{
${ }^{1}$ Psicologia/Kroton-Anhanguera São José dos Campos, Brasil. E-mail: pamelateixeira.sjc@gmail.com.

2 Professor de Psicologia/Kroton- Anhanguera, Brasil. E-mail: jofabiano@gmail.com.

3 Professora de Administração/Kroton- Anhanguera, Brasil. E-mail: anakabanass@gmail.com.
} 